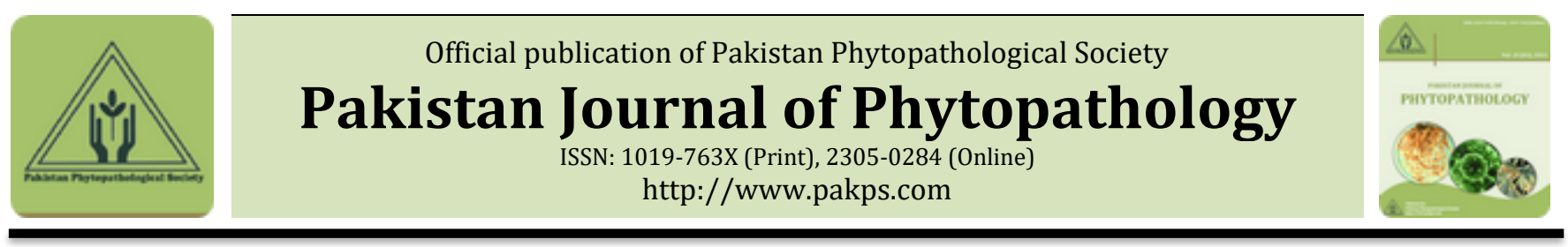

\title{
EFFICIENCY OF SELECTED BOTANICALS AGAINST (ALTERNARIA SOLANI) CAUSING EARLY BLIGHT DISEASE ON TOMATO IN AZAD JAMMU AND KASHMIR
}

\author{
aAsma Bashir, aMuhammad T.-Khan, ${ }^{a}$ Raees Ahmed*, aBasharat Mehmood, \\ ${ }^{a}$ Muhammad T. Younas, a Hafiz M. U. Rehman, bShabir Hussain \\ a Department of Plant Pathology, Faculty of Agriculture, University of Poonch Rawalakot, Rawalakot, AJK. \\ b Department of Agronomy, Bahauddin Zakariya University, Multan, Pakistan.
}

\begin{abstract}
A B S T R A C T
Botanical extracts had proved efficient, cost effective and environment friendly means of plant disease management. Alternaria solani is a fungal pathogen responsible for early blight resulting in huge economic losses. There is dire need for effective cheap alternatives of conventional health hazardous and expensive chemical control. In this study in-vitro evaluation of four plant extracts (Melia azedarach, Cannabis sativa, Achillia millefolium and Datura stramonium) were used against early blight disease on tomato at 3 different concentrations $(10,15$ and $20 \%)$ in complete randomized design. Pathogen was isolated from different tomato growing areas of Rawalakot, purified and multiplied on potato dextrose agar (PDA) followed by hyphal tip method. Food poisoned technique was used for fungal growth inhibition. M. azedarach was found most efficient with $73.18 \%$ inhibition at $20 \%$, followed by C. sativa, D. stramonium and A. millefolium (55.79\%, 37.12\% and 31.9\% respectively) as compared to control (88.2\%). Tomato variety (Roma) was used as experimental material with Completely Randomized Design in the greenhouse experiment. M. azedarach showed highest reduction of early blight disease severity $67.93 \%$ at $20 \%$ concentration followed by C. sativa, D. stramonium and A. millefolium (53.63\%, 43.28\%, and $31.78 \%$ ) respectively while it was $87.3 \%$ in control. Study showed that plant extracts could be used as alternatives of highly expensive, health hazardous chemicals to control early blight disease on tomato.
\end{abstract}

Keywords: Alternaria solani; Fungicides; Plant extracts, Growth inhibition, Disease control.

\section{INTRODUCTION}

Tomato (Lycopersicon esculentum L.) is an obligatory enthusiastic crop of family Solanaceae, originated from Western coastal plains of South America. Tomato is predominant fruit vegetable ranks next to potato on world ranking whereas, as a processing crop it ranks first in the world. Tomato is one of the most popular vegetable of Pakistan, grown on an area of 6,0307 hectares with an average production of $95499 \mathrm{~kg} / \mathrm{ha}$ (FAO, 2016). It contains $90 \%$ water, sugars, vitamins mainly $\mathrm{A}$ and $\mathrm{B}$, dietary fibers, essential amino acids, minerals, antioxidants such as lycopene, carotenoids and

Submitted: August 29, 2020
Revised: November 18, 2020
Accepted for Publication: December 14, 2020
* Corresponding Author:
Email: raees@upr.edu.pk
(C) 2017 Pak. J. Phytopathol. All rights reserved.

phytochemical profile (Davey et al., 2000). Due to its succulent nature tomato is prone to various diseases. Most of the diseases that are prevalent in Azad Jammu and Kashmir are of fungal origin like early, late blight and plant parasitic nematodes like root-knot nematodes (Tariq-Khan et al., 2017; 2020, 2020a) responsible for huge monetary and quality losses. Alternaria solani is responsible for early blight in the area and target the crop during humid summer. Disease is usually characterized by its appearance of brown to dark brown necrotic spots having concentric rings on foliage, stem and fruits. The overzealous and indiscriminate use of most of the synthetic fungicides has created different types of environmental and toxicological problems (Babu et al., 2001) and leads to resistance build-up among the pests as well as pathogens (Engindeniz et al., 2013). Best control is by using a combination of various preventive measures like use of early blight resistant vegetable varieties, destruction of infested plants, and use of fungicides. Alternate method 
economically sustainable, efficient and environment friendly is imperative (Ganie et al., 2013) to be sort out. Many researchers introduced different management strategies and investigated that botanicals are sources of antioxidants which protect the plants against many diseases (Mohana and Raveesha, 2013). Botanical extracts have antimicrobial properties due to secondary metabolites like tannins, terpenoids, alkaloids and flavonoids and antibiotic constituents (Pretorius et al., 2002). They are being used to accomplish management of plant diseases and are successfully documented well adopted. Yadav et al., (2018) compared different treatments of plant extracts with chemicals for radial mycelial growth inhibition of Alternaria solani under in-vitro and in-vivo conditions showing their efficiency to minimize the fungal radial growth. Rawalakot is a temperate area with high rainfall and tomato is grown on every household, and early blight is usual malady to be addressed. Due to low number of plants at household level in kitchen gardening, it was found imperative to evaluate localized botanical extracts to manage the disease. The study has been designed to evaluate the efficiency of the selected botanical extracts against early blight (Alternaria solani) isolates in greenhouse conditions in Rawalakot conditions with moderate temperature and high humidity.

\section{MATERIAL AND METHODS}

\section{Isolation and purification and Identification of fungal}

isolates: An extensive survey of tomato growing areas of Rawalakot was done for the collection of early blight infected plants with symptoms on leaves. Isolation of fungus was done by direct placing of infected leaf portions on PDA after disinfection with $0.5 \%$ sodium hypochlorite solution followed by 4-5 washing and blot drying. Purification of fungal colonies was done using single spore and hyphal tip techniques on PDA plates and were incubated at $28^{\circ} \mathrm{C}$ for 3-7 days. Isolates were identified based on their morphology. Colony morphology with visual observation and using stereo and compound microscope. Spore color and size, presence and absence of septa are recorded under stereo and compound microscope from fully grown A. solani culture plates.

Pathogenicity Test: Pathogenicity test of $A$. solani was carried out under greenhouse conditions. The inoculum was prepared by growing each of tested isolates on PDA medium and incubated at $27^{\circ} \mathrm{C}$ for seven days. Then $10 \mathrm{ml}$ of sterile distilled water was added to each plate and colonies were carefully scraped with a sterile needle to make conidial suspension with concentration $2 \times 10^{4}$ spores/mL (Ganie et al., 2013). To confirm Koch's postulates 3-5 tomato seeds were sown in plastic pots having sterilized soil. Four weeks after the emergence of seedlings, fungal suspension was sprayed using atomizer on tomato leaves with three replications. Distilled water was used as control. After inoculation plants were covered with polyethylene bags to maintain high humidity conditions. After 48 hours bags were removed, and plants were kept under greenhouse conditions and were monitored regularly for the development of disease symptoms. Two weeks after inoculation disease severity was recorded in each treatment and disease intensity was recorded using scale 0-5 (Mayee and Datar, 1986) and found effective (Kumar and Kartikeya, 2013).

\section{Collection of Plant material and Preparation of Botanical} extracts: Four plant species, Hemp (Cannabis sativa), Datura (Datura stramonium), Drake (Melia azedarach) and Yarrow (Achillia millefolium) were selected based on their antimicrobial properties, medicinal values and collected from Rawalakot localities. Leaves were used to prepare the extracts and only hemp seed was included along with leaves. The collected plant material was disinfected with $30 \%$ ethanol followed by washing with distilled water and drying then ground until formation of fine powder. Different concentrations (10, 15 and 20\%) of plant extracts were prepared by dissolving $10 \mathrm{~g}, 15 \mathrm{~g}$ and $20 \mathrm{~g}$ powder in $100 \mathrm{ml}$ distilled water respectively by shaking the suspension overnight in a shaker. After 24 hours, prepared suspension was filtered using whatman No.1 filter paper and stored for further use.

In-vitro evaluation of plant extracts: Antifungal bioassay was done using poisoned food technique. PDA amended with antibiotics (streptomycin) to avoid bacterial contamination and $3 \mathrm{ml}$ of each plant extract. Four-millimeter mycelial disk of 7 days old mature fungal colony was placed at middle of each petri plate. Fungicide (+tive control) and distilled water (-tive control). Inoculated plates were incubated at $27^{\circ} \mathrm{C}$ and were regularly monitored. As soon as, negative control plates were filled up, results were collated and analyzed to calculate the percentage inhibition of mycelia of pathogen using formula (Nisa et al., 2011). Experiment was repeated thrice. Formula for estimation is given under;

$$
\mathrm{PGI}=\frac{\mathrm{C}-\mathrm{T}}{\mathrm{T}} \times 100
$$

Where: $\mathrm{PGI}=$ Percentage growth inhibition; $\mathrm{C}=$ Average colony growth of fungal colonies obtained from control plates; $\mathrm{T}=$ Average colony growth of fungal colonies obtained from treated plates.

Tomato Germplasm: Tomato variety (Roma) was used as experimental material; seeds were collected from Gene Bank NARC, Islamabad. One month-old tomato seedlings were 
transplanted to pots containing sterilized soil with 1:1:1 proportion of sand, soil and compost. All pots were placed on a benchtop in green house at $30{ }^{\circ} \mathrm{C}$ with $65-80 \% \mathrm{RH}$ and watered as required.

Disease severity assessment of treated plants: Efficacy of plant extracts against early blight was estimated in pots. Treatments with 10,15 and $20 \%$ of different plant extracts concentrations were evaluated as foliar treatments on 45days old plants and repeated after 15 days. Extracts were applied at the rate of 33.3 $\mathrm{ml} /$ plant, and negative control with application of distilled water and standard fungicide (Mencozeb) at the rate of $2.5 \mathrm{~g} \mathrm{~L}^{-1}$ of water for comparison with efficiency of plant extracts. In each treatment all tomato plants were inoculated with $20 \mathrm{ml}$ inoculum density having $5 \times 10^{6}$ spores $/ \mathrm{ml}$ after two days of last extracts spraying. After inoculation, plants were covered with polyethylene bags for 48 hours to maintain humidity conditions and establishment of infection. Randomly six leaves from each replication were assessed for disease severity measurement. 0-5 disease rating scale was used for disease intensity measurement (Mayee and Datar, 1986) as previously described. Disease severity index from the pot experiment was calculated by using PSI formula (Percent Severity Index) described as Wheeler (1969).

$$
\text { PSI }=\frac{\text { SIR }}{\text { NoLo }} \times 100
$$

Where; SIR = Sum of individual ratings; NoLo = No of leaves observed; MDS = Maximum Disease scale

\section{STATISTICAL ANALYSIS}

The data collected during laboratory and pot experiment was analyzed using CRD two factor factorial design and treatment means were compared by employing HSD Tukey test at LSD 5\% alpha (Steel et al., 1997).

\section{RESULTS}

Survey and samples collection: Survey of ten different locations of tehsil Rawalakot was done and samples were collected on the basis of symptoms as described in table 1. Samples with spots, lesions and having concentric rings were collected and were further subjected to isolation and purification of fungal isolates.

Table 1. Description of samples collected from different locations of tehsil Rawalakot.

\begin{tabular}{ll}
\hline Locations & Sample Description \\
\hline Char & leaf spots, dark brownish leaf spots \\
\hline Dhamni & leaf lesions, elliptical concentric rings \\
\hline Drake & lesions with dark concentric rings \\
\hline Hussian Kot & brown to black lesions \\
\hline Khrick & chlorotic leaves and lesions \\
\hline Paniola & bull eyed target spot lesions \\
\hline Khaigala & leaf spots, lesions with concentric rings \\
\hline Singola & chlorotic leaves with concentric rings \\
\hline Chak & dark brownish spots \\
\hline Trar & $\begin{array}{ll}\text { Isolation and identification: From the samples collected, } \\
\text { fourteen fungal isolates were observed have grey to olive } \\
\text { green and black aerial mycelia growth. Conidiophores have } \\
\text { dark colored conidia with an average 8-10 transverse and }\end{array}$
\end{tabular}

Figure 1. Cultural, microscopic representation, conidia showing beak and number of septa. 
Pathogenicity Test: Pathogenicity results (Figure 2) showed that all tested isolates of $A$. solani were found able to cause early blight disease with varying degrees of disease severity. Isolate ALT-5 showed highest disease severity (71.5\%) while isolate ALT-1 exhibited lowest disease severity $(11.78 \%)$ on tomato plants (Figure 2; 3). ALT-5 was found most virulent and used for further studies.

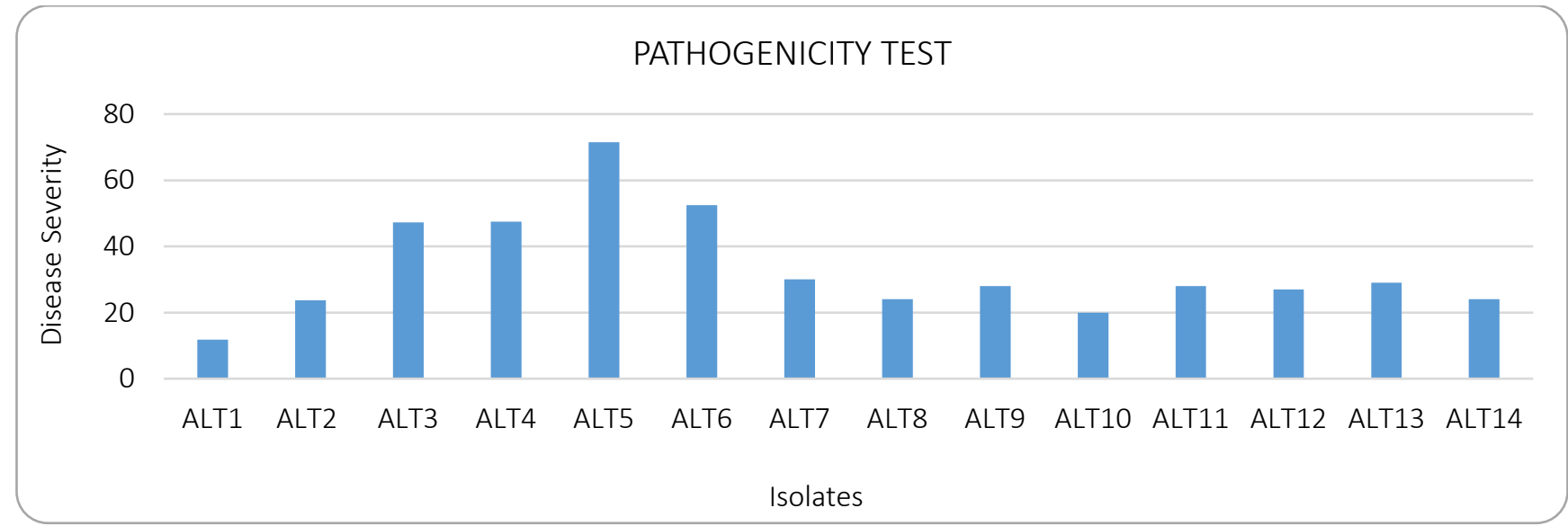

Figure 2. Pathogenicity test of Alternaria solani on tomato plants under greenhouse conditions.

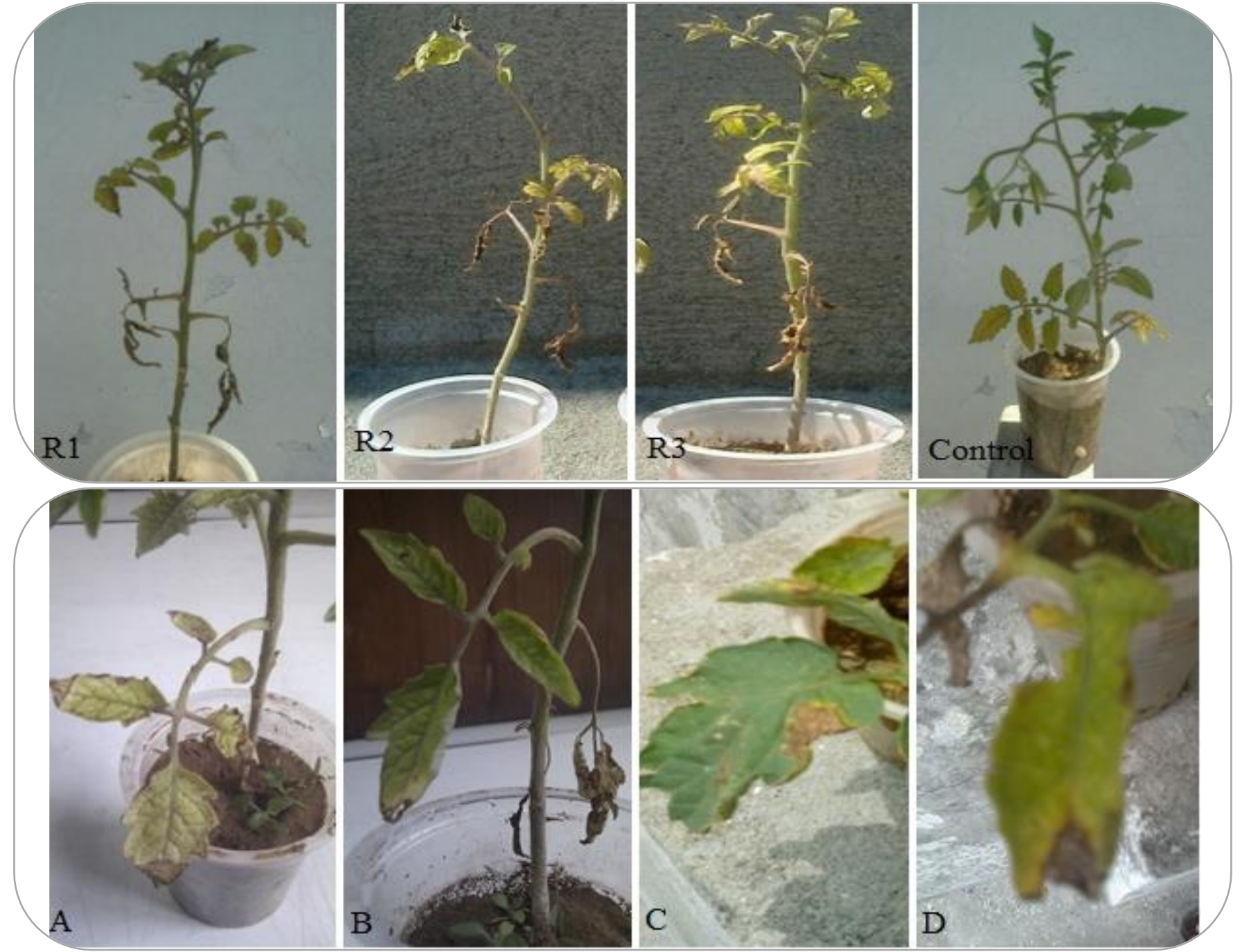

Figure 3. Pathogenicity test plants having symptoms of early blight. 
In- vitro effect of plant extracts on radial mycelial growth: Radial mycelial growth (RMG) means showed that growth of fungus decreased with increase in application of plant extracts. $M$. azedarach was found most effective and efficient against fungal mycelial growth reduction at all concentrations where PDA treated with M. azedarach showed 32.16, $28.00 \mathrm{~mm}$ and $24.00 \mathrm{~mm}$ growth at
10,15 , and $20 \%$ respectively followed by $C$. sativa 44.56, 42.76, $39.73 \mathrm{~mm}$ (Figure 4) while in negative control it was $89.66 \mathrm{~mm}$ growth in colony and in positive control it was $10.10 \mathrm{~mm}$. Results confirmed findings that $A$. indica extract suppressed the growth of fungus (Hassanein et al., 2008). A compound Azadirachtin cause suppression of growth and effective against fungi (Gujar et al., 2012).

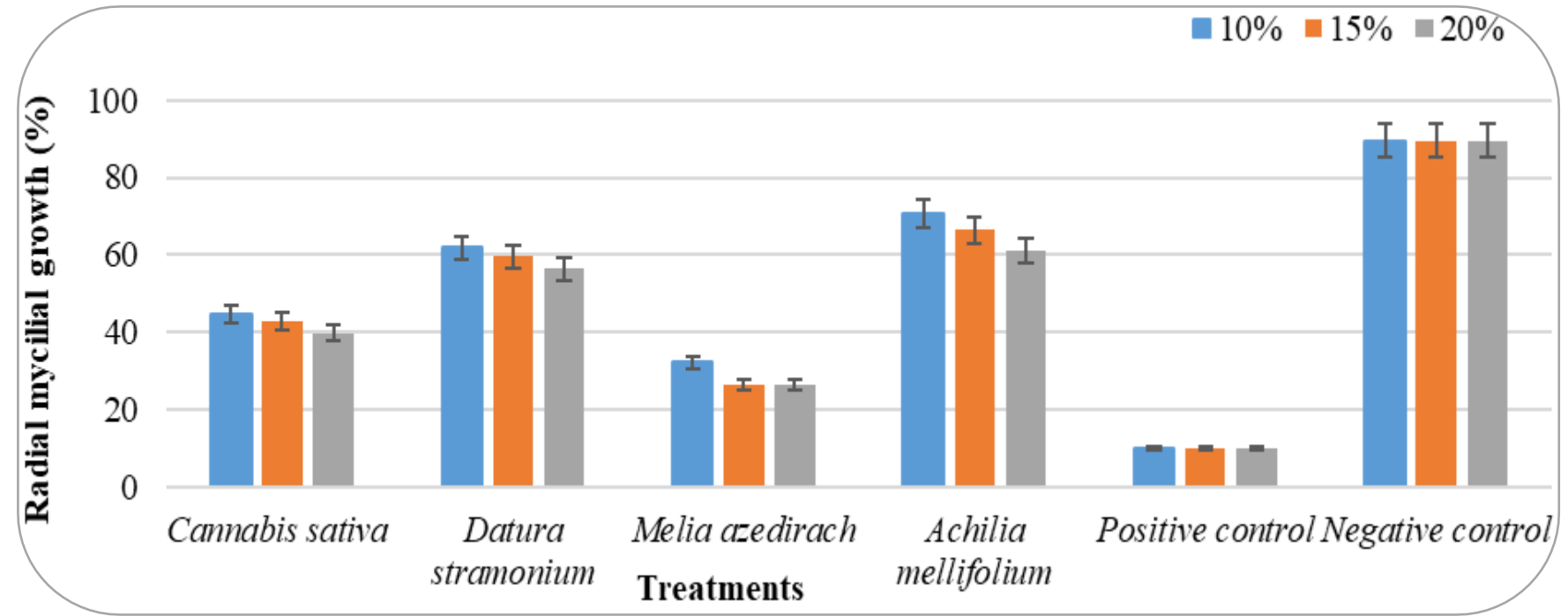

Figure 4. Antifungal activity of plant extracts against Alternaria solani isolate based on radial mycelial growth (mm)

Percentage reduction of RMG of $\boldsymbol{A}$. solani: Maximum respectively (Figure 5). D. stramonium and A. millefolium percentage inhibition was shown by the $M$. azedarach $64.08,68.72$ and $73.18 \%$ at 10,15 and $20 \%$. C. sativa did not show impressive inhibition for disease control. showed 50. 23, 52 and $55.79 \%$ at 10,15 and $20 \%$ Unamaended media did not show inhibition while media treated with Mencozeb showed 88.2\% inhibition.

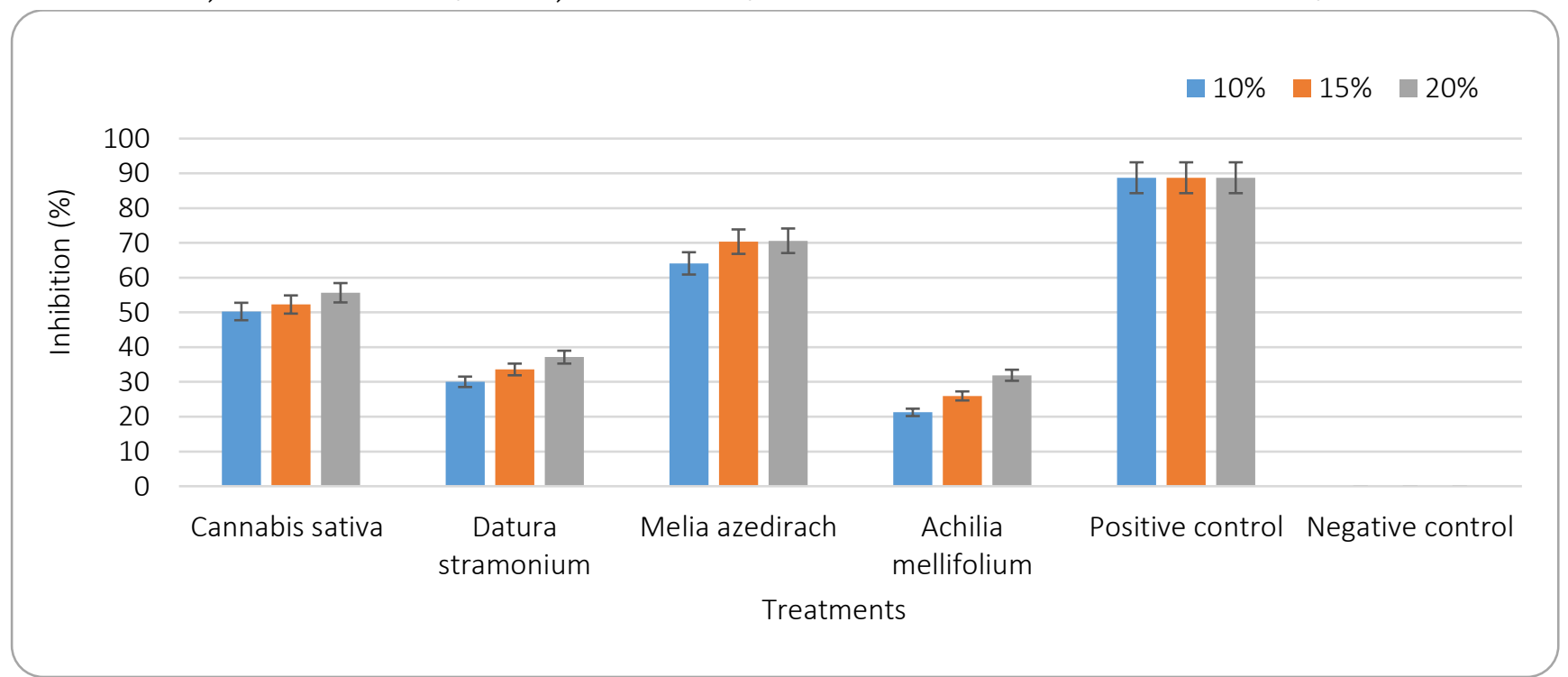

Figure 5. Impact of plant extracts against early blight pathogen (A. solani) in laboratory conditions in petri-plates and colony inhibition

Green House Experimentation and Disease Severity:

Concentrations of plant extracts C. sativa and M. azedarach ominously reduced the early blight disease in pot experiment. Most effective treatment was M. azedarach at 
15 and $20 \%$ concentration, followed by C. sativa at 15 and $20 \%$ concentration. A. millefolium was found with least disease suppression impact on early blight while 80-90\% reduction in disease severity as under fungicide impact. Among four plant extract tested, most effective plant extract was Melia azedarach which exhibited maximum efficacy $67.77,62.93,56.32 \%$ at concentration of 10,15 and $20 \%$ respectively followed by $C$. sativa $43.86,47.84$ and $53.63 \%$ while minimum reduction shown by $A$. mellifolium $31.33 \%$ (Figure 6). Positive control exhibit $87 \%$ efficacy using fungicide (Mencozeb) against early blight disease in in-vivo pot experiment.

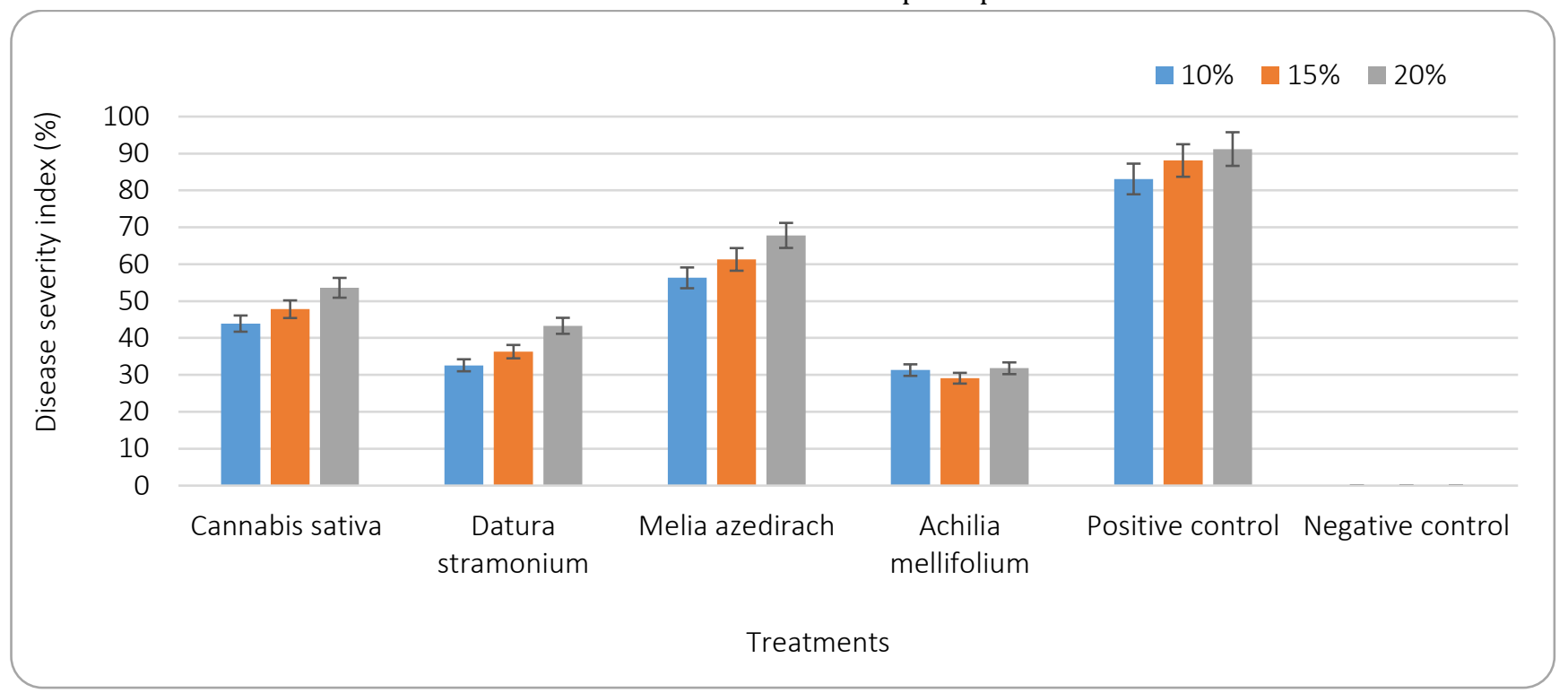

Figure 6. Effect of Four botanical extracts with 3 level concentrations on tomato early blight disease severity

\section{DISCUSSION}

Early blight caused by the fungus Alternaria solani (Ellis and Martin, 2014) is a major disease of tomatoes and potato. Disease is one of the most prevalent and catastrophic to tomato crop, reducing its yield and results in huge losses (Goufo et al., 2008). Use of fungicides is considered as most impressive method for plant disease management but these chemicals are costly and have adverse impacts on environment (Bhandari, 2014). Unjustified and underdose applications due to financial constraints of the poor farmers leads to development of resistance in pathogen against chemicals (Hahn, 2014). It has compelled researchers to look for effective and different approach to reduce reliance on commercial fungicides. Plant extracts are considered as a worthy substitute to fungicides, as they showed antifungal capacity and are also ecofriendly. Certain plants originated secondary metabolites that displayed antifungal action are phenolics, terpenes, tannins, flavonoids, essential oil, alkaloids, polypeptide and lecithin. Such groups of compounds play a substantial role in physiology of plants and thus resulted in reduction of early blight in some of the previous studies (Kagale et al., 2004).
In present research, efficiency of selected plant diffusates $C$. sativa, D. stramonium $M$. azedarach and $A$. millefolium against $A$. solani were studied. Plant extracts tested at three concentration 10, 15 and $20 \%$ each by using food poison technique. All treatments showed significant difference for inhibiting the radial mycelial growth of fungi. Maximum radial mycelium growth was shown by $A$. mellifolium $70 \mathrm{~mm}$ at $20 \%$ concentration and minimum radial mycelial growth was $24.00 \mathrm{~mm}$ by M. azedarach at $20 \%$ concentration as compared to distilled water $89 \mathrm{~mm}$ as negative control and Mancozeb $10.1 \mathrm{~mm}$ positive control. In case of inhibition maximum inhibition $73 \%$ was showed by M. azedarach at $20 \%$ concentration and minimum percent inhibition was $31 \%$ by $A$. mellifolium at $20 \%$ as compared to control (Figure 5). It reveals that Melia azedarach might have improved concentration of ursolic acid, benzoic acid and 3,5 dimethoxy benzoic acid providing antifungal ingredients responsible for early blight control which is needed to be confirmed and also found effective in pervious in-vitro studies against Alternaria leaf blight of tomato with efficiency of $63.52 \%$ (Kumar et al., 2017). It reveals that plant extracts naturally have antifungal properties against early blight. In pot experiment foliar application 
of $33.3 \mathrm{ml}$ plant extracts at $20 \%$ concentration ominously suppressed the disease severity. At 20\% concentration minimum disease severity index was $28 \%$ by $M$. azedarach while maximum severity index was $64 \%$ by $A$. millefolium. Application of $M$. azedarach at $20 \%$ concentration on tomato plants in pots significantly $(\mathrm{P}<$ $0.05 \%$ ) suppressed the growth of $A$. solani (Figures 4; 5; 6). Plant extracts (M. azedarach) are easy to handle plant ailments and different plants extract application on fungal pathogens revealed their highest efficiency against fungal growth. In-vivo results of experiments revealed hexaconazole found in plant leaves are effective (Yadav et al., 2018). Therefore, from the foregoing argument it may accomplished that M. azedarach, a common medicinal plant could be used as effective biofungicide that has vast fungi toxic properties and effective against $A$. solani.

\section{CONCLUSION}

Synthetic fungicides applications are expensive and hazardous to human and animals can be reduced by the applications of botanical extracts, which is environment friendly approach. Plant disease can be reduced with the applications of such botanicals which are easily available to farmers even in their fields. Study confirmed their efficiency and availability to farmers. As in this research, one could confidently suggest that plant extract of Melia azedarach and D. stramonium at $20 \%$ concentration are effective against $A$. solani and can be used to breakdown the resistance in pathogen against conventional synthetic fungicides and reduce the farmer cost as well. These plants can be exploited as alternative used in control of early blight disease under Rawalakot conditions.

\section{REFERENCES}

Babu, S., K. Seetharaman, R. Nandakumar and I. Johnson. 2001. Variation in sensitivity to fungicides among isolates of Alternaria solani causing tomato leaf blight disease. Acta phytopathologica et entomologica hungarica, 36: 251-258.

Bhandari, G. 2014. An overview of agrochemicals and their effects on environment in Nepal. Applied Ecology and Environmental Sciences, 2: 66-73.

D-Steel, R. G. and J. H. Torrie. 1986. Principles and procedures of statistics: a biometrical approach. McGraw-Hill, 400-428pp.

Davey, M. W., M. v. Montagu, D. Inze, M. Sanmartin, A. Kanellis, N. Smirnoff, I. J. J. Benzie, J. J. Strain, D. Favell and J. Fletcher. 2000. Plant L-ascorbic acid: chemistry, function, metabolism, bioavailability and effects of processing. Journal of the Science of Food and Agriculture, 80: 825-860.

Engindeniz, S. and G. O. Cosar. 2013. An economic comparison of pesticide applications for processing and table tomatoes: A case study for Turkey. Journal of Plant Protection Research, 53: 230-237.

Ganie, S., M. Ghani, Q. Nissar, N. Jabeen, Q. Anjum and F. Ahanger. 2013. Status and symptomatology of early blight (Alternaria solani) of potato (Solanum tuberosum L.) in Kashmir valley. African Journal of Agricultural Research, 8: 5104-5115.

Goufo, P., C. T. Mofor, D. Fontem and D. Ngnokam. 2008. High efficacy of extracts of Cameroon plants against tomato late blight disease. Agronomy for sustainable development, 28: 567-573.

Gurjar, M. S., S. Ali, M. Akhtar and K. S. Singh. 2012. Efficacy of plant extracts in plant disease management 3: 425-433.

Hahn, M. 2014. The rising threat of fungicide resistance in plant pathogenic fungi: Botrytis as a case study. Journal of chemical biology, 7: 133-141.

Hassanein, N., M. Abou Zeid, K. Youssef and D. Mahmoud. 2008. Efficacy of leaf extracts of neem (Azadirachta indica) and chinaberry (Melia azedrach) against early blight and wilt diseases of tomato. Aust. J. Basic Appl. Sci, 2: 763-772.

Kagale, S., T. Marimuthu, B. Thayumanavan, R. Nandakumar and R. Samiyappan. 2004. Antimicrobial activity and induction of systemic resistance in rice by leaf extract of Datura metel against Rhizoctonia solani and Xanthomonas oryzae pv. oryzae. Physiological and Molecular Plant Pathology, 65: 91-100.

Kumar, S. and K. Srivastava. 2013. Screening of tomato genotypes against early blight (Alternaria solani) under field condition. The Bioscan, 8: 189-193.

Kumar, V., G. Singh and A. Tyagi. 2017. Evaluation of different fungicides against Alternaria leaf blight of tomato (Alternaria solani). International Journal of Current, Microbiological and Applied Sciences, 6: 2343-2350.

Mayee, C. D. and V. V. Datar, 1986. Phytopathometry, Marathwad Agricultural University, Parabhani. p. 95.

Mohana, D. and K. Raveesha. 2007. Anti-fungal evaluation of some plant extracts against some plant pathogenic field and storage fungi. Journal of 
Agricultural Technology, 4: 119-137.

Nasir, F. and M. S. Khan. 2012. Validation of Some of the Ethnopharmacological Uses of Xanthium strumarium and Duchesnea indica. Pakistan Journal of Botany, 44: 1199-1201.

Paramathma, M., K. Parthiban, V. Muralidharan, R. J. Sudhagar, M. Sujatha, A. J. Prabakaran, P. Durairasu, P. Viswanathan, K. Raj and M. Sivaprakash. 2014. CJ-3 (IC0598611; INGR 14006), a Physic nut (Jatropha curcas L.) Germplasm with High yield, Early Flowering (125 Days) and High Oil Content (38.01\%). Indian Journal of Plant Genetic Resources, 27: 185-187.

Pardey, P. G., R. S. Andrade, T. M. Hurley, X. Rao and F. G. Liebenberg. 2016. Returns to food and agricultural R\&D investments in Sub-Saharan Africa, 19752014. Food Policy, 65: 1-8.

Pretorius, J., P. Zietsman and D. Eksteen. 2002. Fungitoxic properties of selected South African plant species against plant pathogens of economic importance in agriculture. Annals of Applied Biology, 141: 117124.

Tariq-Khan, M., A. Munir, T. Mukhtar, J. Hallmann and H. Heuer. 2017. Distribution of root-knot nematode species and their virulence on vegetables in northern temperate agro-ecosystems of the
Pakistani-administered territories of Azad Jammu and Kashmir. Journal of Plant Diseases and Protection, 124: 201-212.

Tariq-Khan, M., A.-D. A. Khan, M. Saeed, S. Z. Gardazi, B. Mehmood, M. Ilyas and R. Ahmed. 2020. Distribution and virulence of root-knot nematodes on summer vegetables in sudhnuti district of azad jammu and kashmir. Pakistan Journal of Phytopathology, 32.

Tariq-Khan, M., T. Mukhtar, A. Munir, J. Hallmann and H. Heuer. 2020. Comprehensive report on the prevalence of root-knot nematodes in the Poonch division of Azad Jammu and Kashmir, Pakistan. Journal of Phytopathology, 168: 322-336.

Taskeen-Un-Nisa, W. A., M. Y. Bhat, S. Pala and R. Mir. 2011. In vitro inhibitory effect of fungicides and botanicals on mycelial growth and spore germination of Fusarium oxysporum. Journal of Biopesticides, 4: 53-56.

Wheeler, B. E. J. 1969. An introduction to plant diseases. An introduction to plant diseases.

Yadav, V. K., V. Kumar and A. Mani. 2018. Evaluation of fungicides, biocontrol agents and plant extracts against early blight of potato caused by Alternaria solani. International Journal of Chemical Studies, 6 : 1227-1230.

Contribution of Authors:
Asma Bashir
Muhammad T.-Khan
Raees Ahmed
Basharat Mehmood
Muhammad T. Younas
Hafiz M. U. Rehman
Shabir Hussain

: Writing original manuscript

: Reviewed, and edited the manuscript

: Provide technical input in writing manuscript

: Provide technical input in writing manuscript

: Designing of survey format and compilation and interpretation of data

: Draw graphs in Microsoft excel

: Helped in statistical analysis 